\title{
BMJ Open Organisational culture and the integrated chronic diseases management model implementation fidelity in South Africa: a cross-sectional study
}

\author{
Limakatso Lebina (D) ,,2 Mary Kawonga, ${ }^{3}$ Olufunke Alaba, ${ }^{4}$ Natasha Khamisa, ${ }^{3}$ \\ Kennedy Otwombe, ${ }^{1,5}$ Tolu Oni ${ }^{2,6}$
}

To cite: Lebina L, Kawonga M, Alaba 0 , et al. Organisational culture and the integrated chronic diseases management model implementation fidelity in South Africa: a crosssectional study. BMJ Open 2020;10:e036683. doi:10.1136/ bmjopen-2019-036683

- Prepublication history for this paper is available online. To view these files, please visit the journal online (http://dx.doi. org/10.1136/bmjopen-2019036683).

Received 30 December 2019 Revised 03 June 2020 Accepted 10 June 2020

Check for updates

(C) Author(s) (or their employer(s)) 2020. Re-use permitted under CC BY-NC. No commercial re-use. See rights and permissions. Published by BMJ.

For numbered affiliations see end of article.

Correspondence to Dr Limakatso Lebina; lebinal@phru.co.za

\section{ABSTRACT}

Objective To assess whether organisational culture influences the fidelity of implementation of the Integrated Chronic Disease Management (ICDM) model at primary healthcare (PHC) clinics.

Design A cross-sectional study.

Setting The ICDM model was introduced in South African clinics to strengthen delivery of care and improve clinical outcomes for patients with chronic conditions, but the determinants of its implementation have not been assessed.

Participants The abbreviated Denison organisational culture (DOC) survey tool was administered to 90 staff members to assess three cultural traits: involvement, consistency and adaptability of six PHC clinics in Dr. Kenneth Kaunda and West Rand (WR) health districts. Primary and secondary outcome measures Each cultural trait has three indices with five items, giving a total of 45 items. The items were scored on a Likert scale ranging from one (strongly disagree) to five (strongly agree), and mean scores were calculated for each item, cultural traits and indices. Descriptive statistics were used to describe participants and clinics, and Pearson correlation coefficient to asses association between fidelity and culture.

Results Participants' mean age was $38.8(\mathrm{SD}=10.35)$ years, and $54.4 \%(49 / 90)$ were nurses. The overall mean score for the DOC was $3.63(\mathrm{SD}=0.58)$. The involvement (team orientation, empowerment and capability development) cultural trait had the highest (3.71 $\mathrm{SD}=0.72$ ) mean score, followed by adaptability (external focus) (3.62; $\mathrm{SD}=0.56)$ and consistency $(3.56 ; \mathrm{SD}=0.63)$. There were no statistically significant differences in cultural scores between PHC clinics. However, culture scores for all three traits were significantly higher in WR (involvement 3.39 vs $3.84, p=0.011$; adaptability 3.40 vs $3.73, p=0.007$; consistency 3.34 vs $3.68, p=0.034$ ). Conclusion Leadership intervention is required to purposefully enhance adaptability and consistency cultural traits of clinics to enhance the ICDM model's principles of coordinated, integrated, patient-centred care.

\section{INTRODUCTION}

There is often a gap or lag between the growing knowledge of efficacious evidence-based
Strengths and limitations of this study

- The strength of this study is that it addresses an evidence gap from low-income and middle-income countries and contributes to the knowledge of how the public health sector organisational culture might affect the implementation of new interventions.

- The Denison organisational culture survey tool that has been validated in organisations of different sizes and industries and previously used in the South African healthcare context was used to assess the cultural traits of the clinics.

- Three (adaptability, involvement and consistency) cultural traits that could be linked to an organisations performance and objectives such as effectiveness were assessed.

- Some of the limitations of the study are that the research was conducted in only six primary healthcare (PHC) clinics, with a few purposively selected staff members that might be an under-representation of PHC clinics and healthcare workers.

- Although attempts were made to conduct surveys with participants within their places of work where there was privacy, the risk of social desirability bias could have influenced responses.

interventions and public health practice. ${ }^{1-3}$ Implementation science closes this gap by examining the process of how new research findings or interventions are translated into routine practice (implementation) and how contextual and other factors affect implementation. ${ }^{24}$ Effective implementation of interventions is vital for achieving the intended outcomes. ${ }^{5}$ Implementation effectiveness, including fidelity (adherence to intervention guidelines) can be affected by factors relating to the intervention itself, the implementers and the organisational context within which the intervention is applied. ${ }^{5}$ The organisational contextual factors include leadership, policies, skills, funding, communication style, decision-making processes and organisational 
culture ${ }^{5-7}$ Organisational culture needs to be understood and purposefully shaped if necessary as it can either hinder or support implementation fidelity of policies and interventions. ${ }^{8-10}$ However, there is a dearth of studies on how organisational culture affects implementation, especially in low-income and middle-income countries. This innovative study assesses the impact of organisational culture on implementation effectiveness in South Africa, a middle-income country. Specifically, the research uses fidelity as an indicator of implementation effectiveness, focusing on the implementation of a chronic care model in a primary care setting.

\section{Organisational culture and implementation of new innovations} Organisational culture is defined as the shared beliefs, values and behaviour that a group has adopted over a course of time as a way to survive and succeed..$^{10-12}$ Organisational culture is also influenced by the structure and design of an organisation. ${ }^{13}$ It is also regarded as a foundation for organisational management principles and practices. ${ }^{10}{ }^{14} \mathrm{~A}$ culture that is resistant to change could slow down the process and increase the costs of implementing a new intervention. ${ }^{15}$ Whereas a culture that is receptive to new interventions usually has communications processes that promote openness to change and minimises other competing demands. ${ }^{5}{ }^{15}$ A positive culture is one of the contextual factors that accelerates organisational learning and improves the adoption of evidence-based practices. ${ }^{16}$

In the healthcare sector, positive (collaborative, supportive, cohesive and inclusive) organisational culture has been associated with improved service outcomes indicated by patient satisfaction and quality of care. ${ }^{17}$ Implementation of new interventions without understanding the cultural forces might have unpredicted or unwanted outcomes. ${ }^{18}$ For example, a negative culture in an organisation could make staff members have emotional burnout, become depersonalised and less innovative, which negatively affect implementation effectiveness of interventions. ${ }^{18} 19$ Therefore, organisational culture assessments are important as they could assist leaders to understand how organisational culture impacts intervention implementation and other contextual factors, and necessary changes to improve implementation effectiveness, including fidelity. ${ }^{10} 14$

\section{The Denison organisational culture (DOC) model}

There are different recommended models, tools and approaches ${ }^{1320}$ for culture assessment of an organisation, each with varying foci, strengths and weaknesses. ${ }^{9}$ 20-22 The DOC model seemed most appropriate for this study on examining the organisational culture of PHC clinics in South Africa and impacts of culture on implementation of a new intervention-the integrated chronic disease management (ICDM) model. The DOC model approach is appropriate as it focuses on linking the culture to the organisation's objectives and performance indicators like quality and effectiveness. ${ }^{1011} 132023$ The DOC model has been validated and applied previously in 160 organisations of different sizes and industries in the USA, Europe, Asia and Middle East. ${ }^{24}$ The DOC survey has also been used previously in a South African healthcare context, and it is easy to administer and applies to all levels (executive management to workers) of an organisation. ${ }^{2023}$

The DOC model and survey tool was developed following research into various sectors and companies of different sizes to assess four inter-related cultural determinants (traits) that have been linked to bottom-line performance indicators like quality, profit and effectiveness. ${ }^{1011}$ The four (mission, adaptability, involvement and consistency) cultural traits that Denison describes as affecting the organisation's sustainability and long-term effectiveness are as follows ${ }^{10}{ }^{11}$ :

Mission

Long-term strategic intent and direction with clear objectives, and the three indices under mission are strategic direction and intent, goals and objectives and vision.

\section{Adaptability}

The three cultural indices under the adaptability trait are creating change, customer focus and organisational learning. An organisation that has a high score of adaptability is innovative, constantly reviewing the environment and responding appropriately while anticipating upcoming changes. This also includes understanding the customer current and possible future needs and flexibility to change processes and crucial behaviour if necessary.

\section{Involvement}

The three cultural indices of involvement are empowerment, team orientation and capability development. A high level of empowerment in an organisation indicates that employees have a greater sense of ownership and authority to initiate and manage the work. A teamorientated organisation values working cooperatively to complete tasks. Capability development includes investment in developing staff members' skills to give the organisation a competitive advantage.

\section{Consistency}

Core values, agreement and coordination and integration are the three cultural indices under the consistency cultural trait. The core values give employees a clear set of expectations and could make it easier to agree on crucial matters. An organisation that has a high level of coordination and integration is simple to bring staff members from different units to work together.

In the DOC model, successful organisations are the ones that have strengths in all the four cultural traits. ${ }^{1011}$ Although overall balance in all the traits is the objective, the results of the DOC survey can also be used to build on a particular area of the culture ${ }^{10}{ }^{11}$ depending on the objectives of the organisation at a specific time.

In this study, we used the DOC survey to understand how organisational culture has affected the implementation of the ICDM model. 


\section{The ICDM model}

The ICDM is a chronic care model that was introduced in three provinces in South Africa as a pilot implementation phase in $2011 .^{25}$ The ICDM model was developed by the national department of health and cascaded down to the provincial and district health management for implementation..$^{26}$ In the current setting of the South African healthcare system context where primary healthcare re-engineering is a key focus, the ICDM model is among several PHC system strengthening strategies being followed to improve quality of services and patient outcomes. ${ }^{25}$ The ICDM was introduced as a result of an increasing prevalence of non-communicable diseases (accounting for $51.3 \%$ of all deaths) in the background of an epidemic of communicable diseases like HIV/ AIDS and tuberculosis (TB), ${ }^{27}$ which resulted in a surge of multimorbidity, ${ }^{29}$ to which a health system that is fragmented, inefficient and overcrowded is struggling to respond..$^{30} 31$ The following conditions are managed under the nurse-led ICDM model: HIV/AIDS, $\mathrm{TB}$, asthma, diabetes, hypertension, chronic obstructive airway disease, epilepsy and mental health. ${ }^{25}$ The ICDM model is an integral part of the ideal clinic initiative that started in 2013 as part of PHC re-engineering and evolved into the Ideal Clinic Realisation and Maintenance (ICRM) programme in 2014- programme supporting clinics to attain and maintain recommended standards for clinical and other dimensions of quality. ${ }^{32}$

The ICDM model includes prescriptive guidelines on facility restructuring to improve patient flow, clinical supportive management, strengthening of service delivery support systems and assisted self-management. ${ }^{25}$ Other administrative recommendations under the ICDM model include booking of patients, design of waiting areas and consultation rooms and dispensing of medication. ${ }^{25}$ All these are structural initiatives requiring leadership support and change of work routines. Effective management of chronic conditions like diabetes, asthma and heart failure has been enhanced by the chronic care models resulting in less adverse events and better health outcomes. ${ }^{33}$ However, the effectiveness of the ICDM model has not been adequately demonstrated, necessitating the research on how efficiently it has been implemented.

Previous assessments have indicated that some of the factors that may affect the scale-up of this ICDM innovation are cultural factors such as lack of clinical leadership and negative attitudes and behaviour of staff towards prescribed operational changes. ${ }^{26}$ The objective of this study was therefore to apply the Denison model to understand the organisational culture of six PHC clinics that were pilot sites for the implementation of the ICDM model and assess how culture could influence implementation effectiveness. The study uses existing data on fidelity as the marker of implementation effectiveness.

\section{METHODS}

\section{Study design and setting}

This was a cross-sectional study conducted in six PHC clinics in two health districts in South Africa between November 2018 and August 2019, Dr. Kenneth Kaunda (DKK) in North West Province and West Rand (WR) in Gauteng province. This study was part of a larger study assessing the fidelity and costs of implementing the ICDM model in South Africa, ${ }^{34}$ and the fidelity results have been reported comprehensively in another manuscript. ${ }^{35}$

There are 52 health districts across the nine provinces in South Africa, and although the planning supervision and administration is supposed to be decentralised to districts, management is still very centralised with decision making at national and provincial levels. ${ }^{36}$ Both study districts were pilot sites for the ICDM model since 2011. Both districts provide primary care services ranging from community based, through PHC clinics, to district hospital platforms. PHC clinics usually provide primary care services $8-12$ hours a day and managed by facility managers (commonly with a nursing training) who are accountable to the health district management. ${ }^{36}$

As part of the ideal clinic initiative, PHC clinics in South Africa are assessed against multiple service provision and quality standards and can receive a maximum score of $100 \% .{ }^{32}$ In the ICRM programme, clinics that score $\geq 90 \%$ are considered platinum, $\geq 80 \%$ gold, $\geq 70 \%$ as silver and those that score below $70 \%$ as not achieved ideal clinic status. ${ }^{32}$ Over the years, there has been a steady increase in clinics that have been assessed and those that scored $70 \%$ or above increased from 139 to 513 by $2016 .{ }^{32}$

\section{Sampling and study participants}

The six PHC clinics were selected from the 16 clinics included in our broader study analysing the fidelity of implementation (FOI) and cost of implementing the ICDM model. ${ }^{34}$ As part of the broader study, we measured FOI at clinics and applied a similar ICRM programme scale $^{32}$ to categorise clinics into three groups: high (gold: fidelity score $\geq 80 \%$ ), medium (silver: $\geq 70 \%$ and $<80 \%$ ) and low (not achieved: $<70 \%$ ). The FOI criteria was based on the various activities recommended under each of the four components of the ICDM model. ${ }^{32}{ }^{34}$ Each clinic was then scored on each activity according to how accurately it implemented the activities and scores were then summed up per component and overall for each PHC clinic. ${ }^{34} 35$ Eight PHC clinics had high, six PHC clinics had medium and two had low FOI scores. ${ }^{34}{ }^{35}$ The overall FOI was higher in WR health district compared with DKK $(80 \%$ vs $74 \%, \mathrm{p}=0.1409) .{ }^{35}$ For the organisational culture assessment for this paper, we randomly selected two clinics each (with comparable monthly patient loads) from the high, medium and low level of FOI categories. Two clinics (one high and one medium FOI score) were based in WR health district and four (one high, one medium and two low FOI score) in DKK health district.

At each of the six clinics in our sample, the clinic staff members that were involved in the implementation 


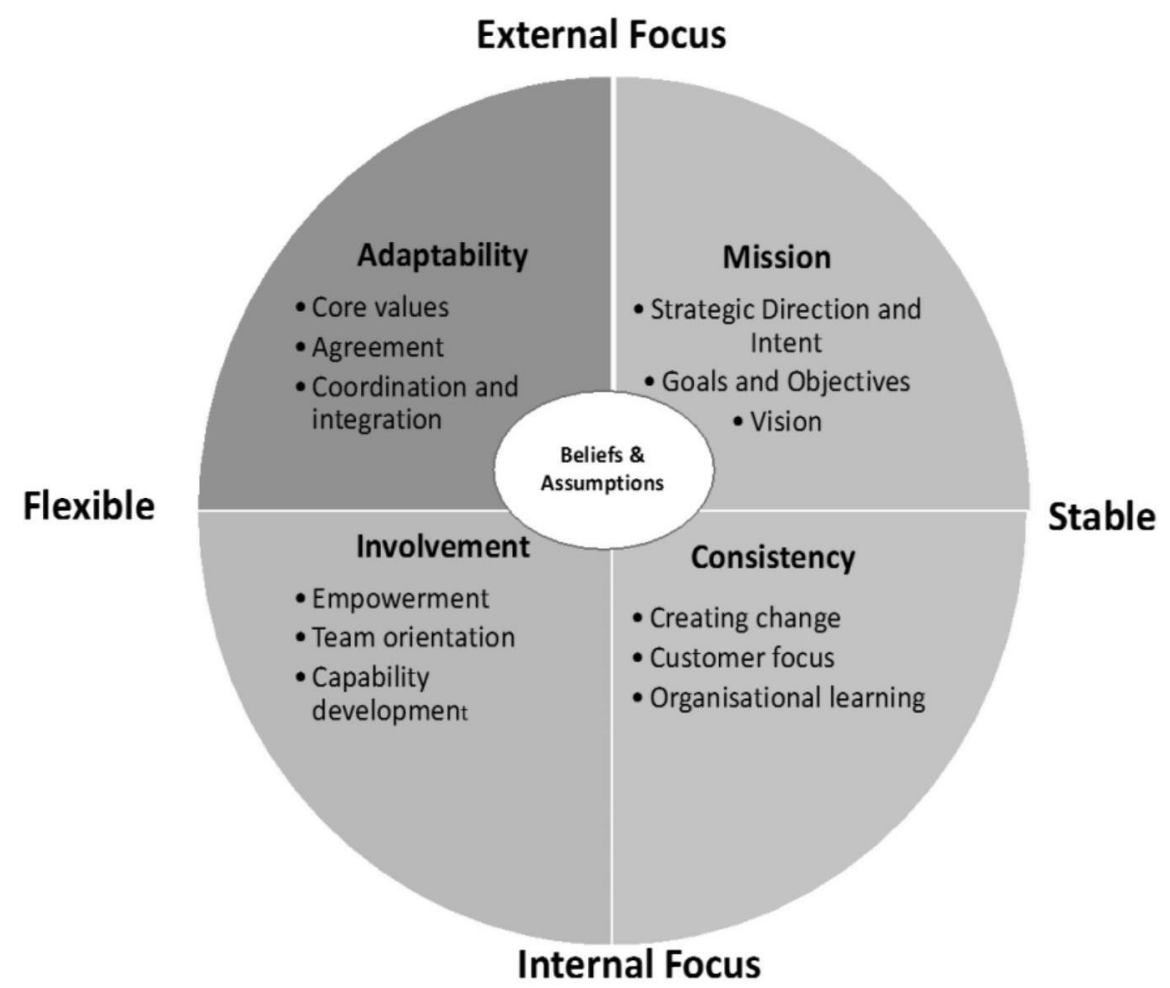

Figure 1 Diagrammatic representation of the Denison organisational culture.

of the ICDM model were eligible for enrolment if they had worked in the study clinic for more than 6 months and were willing to provide written informed consent for participation. All staff members that offer services (administration, adherence support, clinical care and allied health services) to patients with chronic diseases were approached in person to request their participation in the study. We purposively recruited 90 clinical and administrative staff members, 15 per clinic. The sample size calculation was based on a difference of 0.15 in mean scores with $80 \%$ statistical power.

\section{Data collection}

An abbreviated DOC survey tool was used to collect data on the participants' rating of the cultural traits of their respective facilities, with only three of the four cultural traits in Denison's framework were assessed in our study. The mission trait of the DOC framework was not included as long-term strategic and vision development are outlined at district and provincial departments of health levels, not a PHC clinic level. The abbreviated DOC survey tool used in our study therefore assessed the three cultural traits: involvement, consistency and adaptability (figure 1), with each trait comprising three indices. ${ }^{101113}$

Each of the three indices has five items, giving a total of 45 items for our abbreviated Denison scale. Each item is presented as a statement scored on a Likert scale ranging from one to five, with one being strongly disagree and five being strongly agree. The statements are in simple everyday language yet provide a comprehensive analysis of the organisational culture by assessing the underlying cultural traits and management. ${ }^{10}$
In addition, we collected data on the clinic characteristics such as personnel by category, monthly patient headcount for a period of 6 months and ratio of nurse or medical officer to the patient headcount. The number of patients that consult for chronic diseases (HIV/ AIDS, hypertension, diabetes and mental health) per month over the same period and new cases of TB diagnosed per month was included to compare workloads of clinics. Existing data on FOI of the ICDM model was used to compare the overall level of fidelity and on the four (facility reorganisation, clinical supportive management, assisted self-management and strengthening of support systems) major components of the ICDM model.

Interpretation of results

The guidelines provided in the literature on the DOC survey ${ }^{101124}$ were followed in the interpretation of the results of the survey. The focus of the DOC model is to link organisational culture scores and key performance indicators like innovation, quality and employee and customer satisfaction. ${ }^{11}$ For example, high scores on involvement and consistency indicate the strength of internal focus and that the organisation has quality operations and high employee satisfaction, ${ }^{11}$ while high scores in adaptability and involvement demonstrate a flexible organisation that is innovative and strives to understand the external environment and meet the needs of their clients. ${ }^{11}$ Therefore, the DOC survey results can be linked to the organisations' goals to identify gaps that need to be addressed. ${ }^{11}$

Data were collected by trained research assistants interviewing the 90 participants using the paper-based 
abbreviated DOC survey. The research assistants explained the study, the survey tool, interviewed participants and manually completed the survey tool. All interviews were conducted in English and or Zulu/Sotho/Tswana. A few of the participants requested to complete the survey on their own.

\section{Data management and analysis}

The collected data were captured into a REDCap electronic database. ${ }^{37}$ As part of the data quality management plan, data were checked for missing variables, obvious discrepancies, incorrect data and amended appropriately. The data were exported from REDCap into Excel and Statistical Package for Social Science (SPSS V.25) for analysis. ${ }^{38}$ Descriptive statistics (means, SD and proportions) were calculated to describe the demographics of the participants and clinics' characteristics. Six questions in the survey tool were negatively worded,${ }^{24}$ and the scores for those questions were reversed prior to analysis. The abbreviated DOC score was determined by calculating the mean score from the three cultural traits scores. Data were largely complete with only two questions with missing data. For these, we conducted a complete case analysis where the denominators were adjusted accordingly. Descriptive statistics (mean scores and SD) were used to describe the overall PHC clinic organisational culture score and mean scores for each of the three traits based on the DOC survey guidelines and examples. ${ }^{10} 24$ The Pearson correlation coefficient was calculated to measure the association between DOC scores and the degree of FOI of the ICDM model. In addition, clustered univariate and multivariate modelling was conducted to assess the risk factors for low culture scores. We used the independent sample t-test, $\chi^{2}$ and the one way analysis of variance (ANOVA) to assess for statistically significant differences in clinic characteristics, participants demographics and DOC scores between clinics with high, medium and low ICDM model FOI scores. The level of significance was set at 0.05 . The Cronbach's alpha test was calculated for three cultural traits and nine cultural indices.

\section{Patient and public involvement}

In this study, we conducted the survey among healthcare workers only. Patients or the public were not involved in the design, or conduct, or reporting, or dissemination plans of our research.

\section{Ethical approvals}

The participants provided individual written informed consent. Each facility and participant were allocated a study identification number, and no identifiers were included in the electronic password-protected database.

\section{RESULTS}

Characteristics of clinics and participants demographics

Of the 90 staff members enrolled in the abbreviated DOC survey and interviewed, almost half $(49 / 90 ; 54.4 \%)$ were nurses. Others were administrative personnel (data capturers and administrators) $(18 / 90 ; 20 \%)$ and counsellors/health promoters/support staff (23/90; 25.6\%). These participants had been working in their roles for a mean of $6.4(\mathrm{SD}=6.26)$ years. The mean age of the participants was $38.8(\mathrm{SD}=10.35)$ years, and $86.7 \%(78 / 90)$ were women (table 1), and there were no significant differences in the demographics of participants across the three clinic categories by FOI. A mean of 2420 ( $\mathrm{SD}=592.47)$ patients above 20 years received healthcare services per month per clinic. There were no significant differences in the number of personnel and ratio of nurse or medical officer to patients between clinics with a high, medium or low FOI scores (table 1). However, the overall FOI of the ICDM model for the activities of the four components scores was significantly different $(p=0.001)$ with the one-way ANOVA test. Further analysis indicated that the difference was significant between the high and low fidelity $(\mathrm{p}=0.002)$ and between the low and the medium, as well as the high and medium ( $\mathrm{p}=0.013)$, fidelity level clinics.

\section{DOC scores}

\section{Cultural traits}

The Cronbach's alpha test of reliability for the overall survey was 0.94 (table 2). The Cronbach's alpha test for involvement was 0.89 , while for consistency was 0.86 and adaptability was 0.81 . The overall mean DOC score was $3.63(\mathrm{SD}=0.58)$. The involvement cultural trait had the highest mean score (3.71; $\mathrm{SD}=0.72)$, followed by adaptability (3.62; $\mathrm{SD}=0.56)$ and consistency $(3.56 ; \mathrm{SD}=0.63)$.

\section{Cultural indices}

The top three mean scores on the indices of the DOC survey (table 2) were on team orientation $(3.88 ; \mathrm{SD}=0.90)$, core values $(3.79 ; \mathrm{SD}=0.68)$ and empowerment (3.76; $\mathrm{SD}=0.89)$. The lowest three mean scores were on creating change $(3.44 ; \mathrm{SD}=0.76)$, agreement $(3.44 ; \mathrm{SD}=0.80)$ and coordination and integration $(3.45 ; \mathrm{SD}=0.78)$. Capability development $(3.47 ; \mathrm{SD}=0.74)$ was the lowest under involvement trait. Customer focus $(3.67 ; \mathrm{SD}=0.66)$ scored lower than organisational learning $(3.75 ; \mathrm{SD}=0.65)$ under the adaptability cultural trait. Core values scored higher (3.79; $\mathrm{SD}=0.68)$ than agreement $(3.44 ; \mathrm{SD}=0.80)$ under the consistency trait. The Cronbach's alpha test of reliability for the nine cultural indices ranged from 0.58 to 0.82 (table 2). The cultural indices with low Cronbach's alpha test were included in the analysis as the content of the questions had been validated in other settings and in South Africa. ${ }^{20} 2324$

\section{Comparison between high, medium and low FOI clinics}

The overall pattern of the organisational culture of the three sets of clinics was similar, with features like the lower score on capability development compared with empowerment and team orientation under involvement trait and core values attaining a higher score than agreement and coordination and integration under consistency trait. 
Table 1 Characteristics of high, moderate and low implementation fidelity clinics

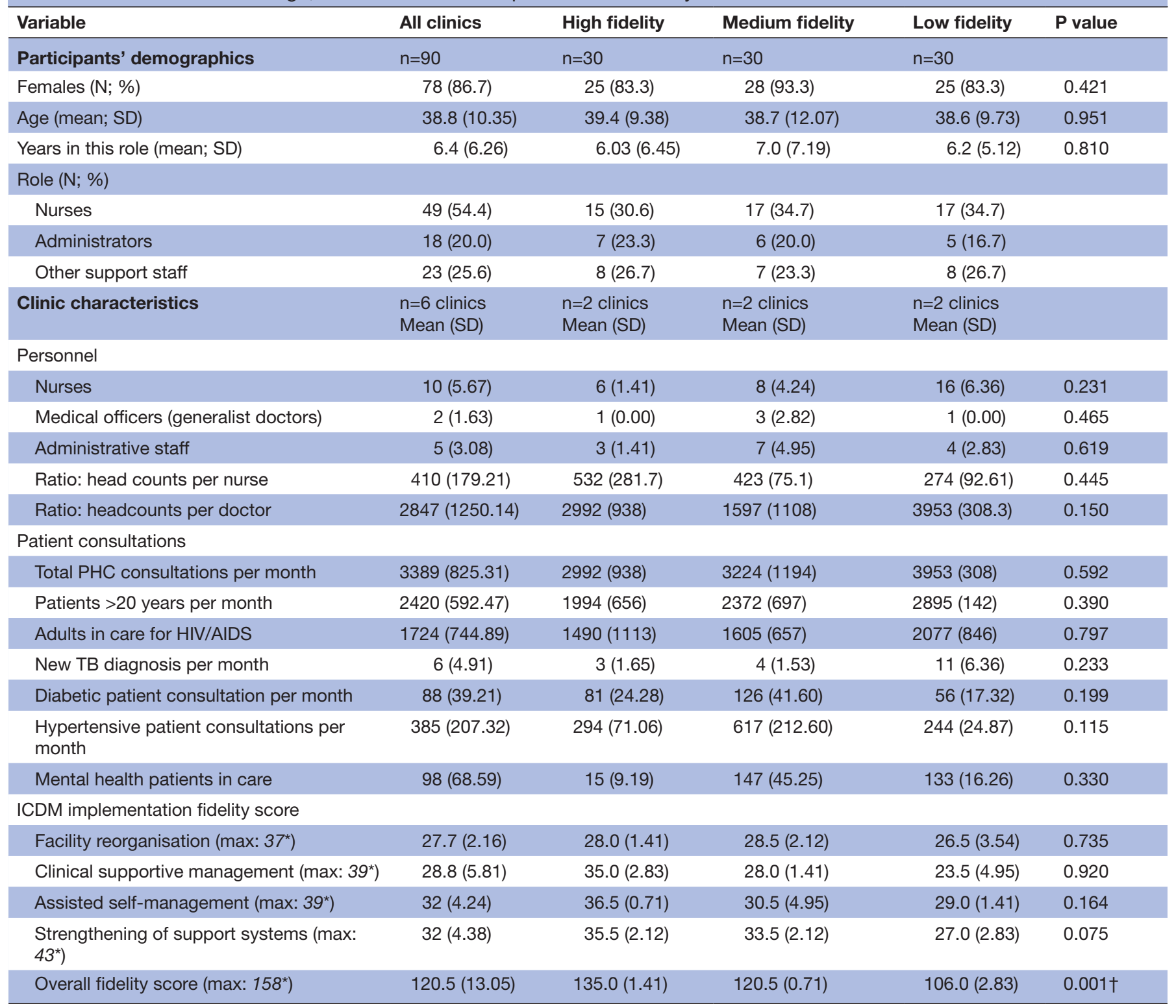

${ }^{*}$ Max=maximum possible fidelity score.

†Statistically significant at the 0.05 .

ICDM, Integrated Chronic Disease Management; PHC, primary healthcare; TB, tuberculosis.

The low FOI clinics attained higher scores on all the three cultural traits: involvement $(3.87 ; \mathrm{SD}=0.64)$, consistency (3.66; $\mathrm{SD}=0.50)$ and adaptability $(3.66, \mathrm{SD}=0.55)$. When comparing the PHC clinics' DOC indices, the low fidelity level clinics had higher scores on three (team orientation, core values and empowerment) indices compared with the medium and high-fidelity clinics (table 2). The differences on mean scores of cultural traits and indices between the three groups of clinics were not statistically significant.

Pearson's correlation coefficient

There was a weak negative correlation between the overall FOI of the ICDM model and the DOC scores $(r=-0.117 ; \mathrm{p}=0.272)$. A similar association was also observed with facility reorganisation $(r=-0.114 ; \mathrm{p}=0.287)$, clinical supportive management $(r=-0.184 ; \mathrm{p}=0.083)$ and strengthening of support systems $(r=-0.123 ; \mathrm{p}=0.247)$ fidelity scores and culture scores. However, there was a weak positive correlation between fidelity scores on assisted self-management and DOC mean scores $(r=0.076$; $\mathrm{p}=0.474$ )

Comparison between the two health districts

At the health district level, there were statistically significant differences on all three (involvement, consistency and adaptability) cultural traits (table 3). Consistency cultural trait scored the lowest in both health districts. When comparing the DOC indices mean scores across the two health districts, DKK health district had higher 
Table 2 The abbreviated Denison organisational culture scores: comparing high, medium and low ICDM model implementation fidelity in PHC clinics

\begin{tabular}{|c|c|c|c|c|c|c|c|c|c|c|}
\hline \multirow[b]{3}{*}{ Cultural traits } & \multirow[b]{3}{*}{ Culture indices } & \multirow{2}{*}{\multicolumn{2}{|c|}{$\begin{array}{l}\text { Overall mean } \\
\text { scores for all PHC } \\
\text { clinics }\end{array}$}} & \multicolumn{6}{|c|}{ Level of implementation fidelity of the ICDM model } & \multirow[b]{3}{*}{$P$ value } \\
\hline & & & & \multicolumn{2}{|c|}{$\begin{array}{l}\text { High PHC Clinics } \\
\mathrm{n}=30\end{array}$} & \multicolumn{2}{|c|}{$\begin{array}{l}\text { Medium PHC Clinics } \\
\mathrm{n}=30\end{array}$} & \multicolumn{2}{|c|}{$\begin{array}{l}\text { Low PHC Clinics } \\
\mathrm{n}=30\end{array}$} & \\
\hline & & Mean & SD & Mean & SD & Mean & SD & Mean & SD & \\
\hline \multirow[t]{4}{*}{ Involvement } & $\begin{array}{l}\text { Empowerment } \\
(\alpha=0.82)\end{array}$ & 3.76 & 0.89 & 3.66 & 0.96 & 3.65 & 0.84 & 3.99 & 0.84 & 0.246 \\
\hline & $\begin{array}{l}\text { Team orientation } \\
(\alpha=0.82)\end{array}$ & 3.88 & 0.90 & 3.95 & 0.89 & 3.64 & 1.05 & 4.05 & 0.68 & 0.177 \\
\hline & $\begin{array}{l}\text { Capability } \\
\text { development }(\alpha=0.58)\end{array}$ & 3.47 & 0.74 & 3.49 & 0.69 & 3.35 & 0.71 & 3.57 & 0.83 & 0.533 \\
\hline & $\begin{array}{l}\text { Overall involvement } \\
\text { cultural trait }(\alpha=0.89)\end{array}$ & 3.71 & 0.72 & 3.70 & 0.77 & 3.55 & 0.74 & 3.87 & 0.64 & 0.228 \\
\hline \multirow[t]{2}{*}{ Consistency } & Core values $(\alpha=0.67)$ & 3.79 & 0.68 & 3.72 & 0.71 & 3.65 & 0.68 & 4.01 & 0.60 & 0.098 \\
\hline & Agreement $(\alpha=0.72)$ & 3.44 & 0.80 & 3.46 & 0.86 & 3.30 & 0.93 & 3.56 & 0.58 & 0.453 \\
\hline \multirow[t]{5}{*}{ Adaptability } & $\begin{array}{l}\text { Creating change } \\
(\alpha=0.72)\end{array}$ & 3.44 & 0.76 & 3.39 & 0.83 & 3.37 & 0.73 & 3.55 & 0.72 & 0.595 \\
\hline & $\begin{array}{l}\text { Customer focus } \\
(\alpha=0.59)\end{array}$ & 3.67 & 0.66 & 3.70 & 0.62 & 3.67 & 0.70 & 3.63 & 0.67 & 0.926 \\
\hline & $\begin{array}{l}\text { Organisational } \\
\text { learning }(\alpha=0.58)\end{array}$ & 3.75 & 0.65 & 3.63 & 0.65 & 3.81 & 0.62 & 3.80 & 0.67 & 0.490 \\
\hline & $\begin{array}{l}\text { Overall adaptability } \\
\text { cultural trait }(\alpha=0.81)\end{array}$ & 3.62 & 0.56 & 3.58 & 0.59 & 3.62 & 0.56 & 3.66 & 0.55 & 0.839 \\
\hline & $\begin{array}{l}\text { Overall Denison } \\
\text { organisational culture } \\
(\alpha=0.94)\end{array}$ & 3.63 & 0.58 & 3.60 & 0.66 & 3.55 & 0.59 & 3.73 & 0.50 & 0.476 \\
\hline
\end{tabular}

$\alpha=$ Cronbach's alpha reliability coefficient.

Overall values are given in bold.

ICDM, Integrated Chronic Disease Management; PHC, primary healthcare.

scores on all the nine indices, and the difference was statistically significant on creating change, core values and team orientation (figure 2). In both health districts, agreement scored lower than coordination and integration and core values under the consistency cultural trait.

The highest scoring cultural indices in WR were customer focus (3.65; $\mathrm{SD}=0.64)$, organisational learning $(3.51, \mathrm{SD}=0.56)$ and core values $(3.49, \mathrm{SD}=0.77)$, while in

Table 3 The abbreviated Denison organisational culture traits mean scores results compared between the two health districts

\begin{tabular}{|c|c|c|c|c|c|}
\hline \multirow[b]{2}{*}{ Cultural traits } & \multicolumn{2}{|c|}{$\begin{array}{l}\text { WR health } \\
\text { District } \\
\mathrm{n}=30\end{array}$} & \multicolumn{2}{|c|}{$\begin{array}{l}\text { DKK health } \\
\text { District } \\
\mathrm{n}=60\end{array}$} & \multirow[b]{2}{*}{$P$ values } \\
\hline & Mean & SD & Mean & SD & \\
\hline Involvement & 3.39 & 0.87 & 3.84 & 0.60 & $0.011^{*}$ \\
\hline Adaptability & 3.40 & 0.54 & 3.73 & 0.54 & $0.007^{*}$ \\
\hline Consistency & 3.34 & 0.77 & 3.68 & 0.52 & $0.034^{*}$ \\
\hline
\end{tabular}

*Statistically significant at the 0.05 level.

DKK, Dr. Kenneth Kaunda; WR, West Rand.
DKK, it was team orientation $(4.1, \mathrm{SD}=0.70)$, core values (3.94; $\mathrm{SD}=0.57)$ and empowerment $(3.92 ; \mathrm{SD}=0.76)$. Controlling for gender, the clustered multivariate analysis showed that clinics in WR health district are associated with lower mean organisational culture scores compared with clinics in DKK health district (table 4).

\section{DISCUSSION}

This study provides timely information on the organisational culture of six PHC clinics that were assessed for the implementation fidelity of the ICDM model and how culture could have affected the implementation fidelity of this intervention. Organisational culture improvements are the focus of many healthcare organisations. ${ }^{8}$ The overall pattern of the DOC survey for the six clinics shows PHC clinics have a balanced both the internal (involvement and consistency) and external (adaptability) focus. The abbreviated DOC survey showed good reliability. The abbreviated DOC survey results showed that the strongest cultural trait was involvement, and adaptability and consistency scored the lowest. The highest scoring cultural 


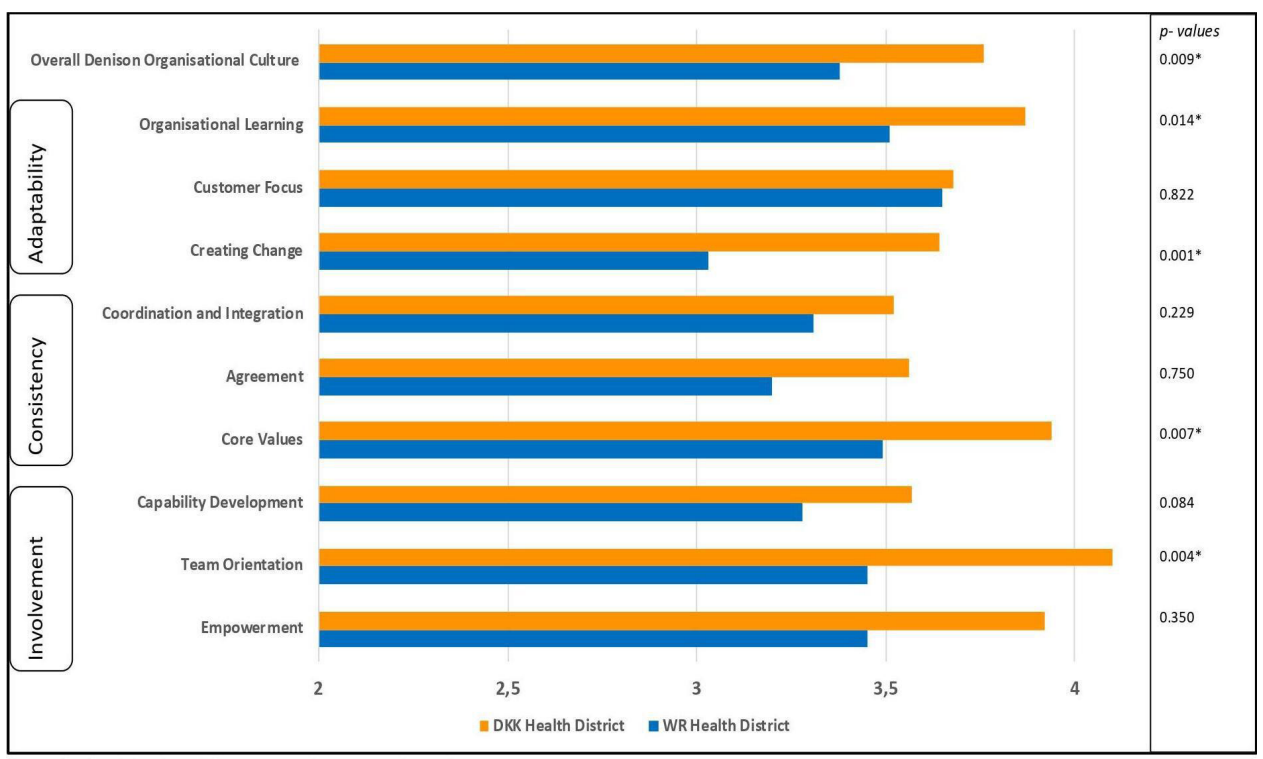

Figure 2 The abbreviated Denison organisational culture indices and mean scores comparing the two health districts. ${ }^{*}$ Statistically significant at the 0.05 level. DKK, Dr. Kenneth Kaunda; WR, West Rand.

indices were team orientation, core values and empowerment and the lowest were creating change, agreement and coordination and integration. In the involvement trait, capability development scored the lowest compared with empowerment and team orientation. Core values scored higher than coordination and integration, and agreement under the consistency cultural trait. Creating change was the lowest scoring index under adaptability trait, compared with customer focus and organisational learning. Organisational learning scored the highest in the low and medium FOI clinics. There was a weak negative correlation between organisational culture and the degree of FOI of the ICDM model. Organisational culture is a critical contextual factor, yet we did not observe a statistically significant differences in mean scores of cultural traits and indices between the clinics that had low, medium and high FOI of the ICDM model. However, there were some statistically significant differences between the two health districts on all three cultural traits (involvement, consistency and adaptability) and indices (creating change, core values and team orientation). WR district was associated with lower mean culture scores.
The strongest cultural trait in these six clinics that participated in the study was involvement, adaptability and consistency had lower scores. Involvement cultural trait covers empowerment, team orientation and capability development. These are indispensable cultural strengths for an organisation that is aiming to improve the performance indicators and quality of services. ${ }^{24}$ Employee involvement has been positively associated with a large number of significant changes in quality care improvements and chronic illness management as engaged employees collaborate, perform at a higher level and are innovative. ${ }^{9}{ }^{39}$ A qualitative study on constraints for adopting health innovations into practice indicated that the hierarchical culture of the South African health system does not support innovation and creating change at facility level. ${ }^{40}$ Creating change cultural index also obtained a low score in this study. Decisions on what new innovative interventions to be introduced are usually concluded at higher (district and provincial) management level with very little bottom-up communication or consultation. ${ }^{40}$ Adaptability cultural trait is a critical strength in an organisation that is undergoing a

Table 4 Clustered univariate and multivariate analysis of the factors associated with Denison organisational culture mean scores

\begin{tabular}{lllll}
\hline & Univariate & & Multivariate \\
\cline { 2 - 3 } Variable & Beta Coefficient (SE) & P value & & Beta Coefficient (SE) \\
\hline Overall fidelity score & $-0.006(0.008)$ & 0.499 & \\
District: WR versus DKK & $-0.381(0.083)$ & 0.010 & $-0.379(0.082)$ \\
Age & $-0.0002(0.006)$ & 0.971 & \\
Gender: female versus male & $-0.030(0.178)$ & 0.874 & $-0.048(0.175)$ \\
Role: clinical versus non-clinical & $0.008(0.123)$ & 0.952 & 0.793 \\
\hline
\end{tabular}

DKK, Dr. Kenneth Kaunda; WR, West Rand. 
transformation, ${ }^{11}$ and this trait would need to be fortified in these PHC clinics as part of the primary healthcare re-engineering. Adaptability cultural trait is even more crucial in this setting as the proposed changes under the ICDM model support customer focus and coordination and integration.

In the six clinics that participated in this study, team orientation, core values and empowerment scored the highest on the DOC survey. A lower score for capability development compared with empowerment and team orientation might indicate that some employees in the PHC clinics are making decisions that they may not be capable of making and comply with team dynamics without much commitment and ownership. ${ }^{11}$ A high level of teamwork and involvement were also observed in another study that assessed organisational culture in an HIV programme, and this protected the staff members from burnout, emotional exhaustion and depersonalisation. ${ }^{19}$ In a study on organisational values and culture of primary healthcare services in Cape Town, South Africa, the cultural values that were aligned with primary healthcare re-engineering were teamwork and community partnership. ${ }^{41}$

The lowest scoring indices were creating change, agreement and coordination and integration in our study. A higher score for core values compared with agreement (under the consistency trait) might imply that even if the organisation has good intentions, the leadership is unresponsive to employees' concerns. ${ }^{11}$ In the adaptability cultural trait, organisational learning scored higher than customer focus, which suggests that the organisation might be excellent at recognising best practices and creating new guidelines but unable to translate this knowledge into routine practice. ${ }^{11}$ An ideal organisational culture in the healthcare sector is one that emphasises patient-centred care (customer focus) and fosters less emphasis on profits. ${ }^{8}$ A supportive cultural environment that is characterised by team orientation, customer orientation, collaboration and sharing of information was the most desired cultural trait by staff members overemphasis on rewards cultural qualities in a PHC setting in Cyprus. ${ }^{42}$

Capability development scored the lowest compared with empowerment and team orientation in the involvement trait. Although empowerment and team orientation are important organisational culture strengths, capability development is also essential to enhance staff skills and engagement in the implementation of new changes in an organisation. ${ }^{43}$ In the consistency cultural trait, core values scored higher than coordination and integration, and agreement.

Customer focus was scored lower in the medium and low FOI clinics compared with high FOI clinics. Patient experience was also observed to have a low organisational value in primary healthcare service in Cape Town metro. ${ }^{41}$ The employees in private health facilities in South Africa have been reported to view customer focus as the strongest cultural index of their organisation and scored coordination and integration and empowerment lower. ${ }^{20}$ The organisational culture in the private health sector is different from the public health sector in that the customer focus was scored higher than the organisational learning and creating change, which might denote that the sector understands the current needs of their customers but is not anticipating and preparing for future changes in the external environment. ${ }^{1020}$ The inference from this survey as perceived by other researchers is that South Africa has adequate legislature and guidelines to provide quality health services, but governance and stewardship need to be improved to achieve these good intentions. ${ }^{30} 44$ The implementation fidelity of the ICDM model would have been facilitated by a culture that is customer focused as the objectives of the model are to improve patient satisfaction with the service and their health outcomes. ${ }^{25}$ Similarly, it is also a good intervention to introduce to organisations that have low coordination and integration cultural index.

There were no statistically significant differences in mean scores of cultural traits and indices between the clinics that had low, medium and high implementation fidelity of the ICDM model, although the low fidelity clinics had three higher scores. Lack of statistically different organisational culture mean scores could have been due to low numbers of clinics and participants and that the fidelity scores were the summation of scores for multiple activities. ${ }^{35}$ In another study on organisational culture conducted among staff members from 42 PHC facilities, the differences on predominant cultural dimensions were observed between gender groups, years of experience in their role and not at clinic level. ${ }^{42}$ Gender, age and role were not correlated with DOC survey results in this study. When comparing the DOC survey results between the two health districts, there were statistically significant differences in all the three cultural traits and three indices (creating change, core values and team orientation). The consistent cultural traits scoring between the clinics that had low, medium and high implementation fidelity of the ICDM model and significantly different scores by health districts might also be an indication of the impact of central management of PHC facilities by the health district leadership. ${ }^{36}$ Desired and experienced cultural values were noted to be similar for healthcare workers based in two health districts in a Botswana study. ${ }^{45}$

Many healthcare organisations have commenced organisational culture enhancements and purposefully influence the cultural environment to be conducive to effective implementation of policies and interventions. ${ }^{89}$ For example, a 2-year 'Leadership Saves Lives' intervention that aimed to support hospitals to improve their culture and promote learning, psychological safety, commitment and senior management support have resulted in improvements in the use of evidence-based strategies and better health outcomes. ${ }^{16}$ Adherence to clinical guidelines on treating tobacco use in a PHC setting was shown to be associated with 'group' (human resource development) and hierarchical (stable) cultural context. ${ }^{46}$ In our study setting, any interventions that 
promote organisational cultural changes will need to include the district leadership and not just focus at the PHC clinic level. Cultural changes also require a high level of leadership support to foster the new mission and provide the necessary resources to implement the change. ${ }^{43}$ There is evidence that cultural changes are feasible and sustainable especially if the vision is aligned with actions, the change implementation is collaborative and small-scale at a time. ${ }^{43}$ Some of the recommendations for organisational change in the study clinics to promote effective implementation of the ICDM model could include an emphasis on customer feedback processes and rewarding staff members that demonstrate patientcentred care as part of improving customer focus. A participatory management style has also been recommended as another strategy to facilitate bottom-up communication and consultation and innovations adoption. ${ }^{40}$ Organisational culture assessments as well as strategies on how to shape the culture needs to be in place prior to introduction of new interventions.

\section{Strengths and limitations}

A key strength of this study is that it addresses an evidence gap from low-income and middle-income countries and contributes to the knowledge of how public health sector organisational culture might affect the implementation of new interventions. In addition, we used the DOC survey tool that has been validated in organisations of different sizes and industries and previously used in the South African healthcare context to assess the cultural traits of the clinics. Furthermore, three (adaptability, involvement and consistency) cultural traits that could be linked to an organisations performance and objectives such as effectiveness were assessed. The study had a number of limitations. The research was conducted in only six PHC clinics, with a few purposively selected staff members that might be an under-representation of PHC clinics and healthcare workers. There is potential for social desirability bias as the survey was conducted with employees while at their place of work. The risk of this bias was limited by ensuring privacy for the interview. In addition, the face-to-face nature of interviews conducted by the researchers could have resulted in interviewer bias. Lastly, the results from these clinics were not compared with other organisations within the large DOC global database as recommended ${ }^{11}$ due to costs.

\section{CONCLUSION}

This is a timely study that provides more understanding of the organisational cultural environment in PHC clinics that are the focus of healthcare system reform. The strongest organisational cultural trait in these clinics was involvement, while consistency and adaptability were their weaker cultural traits. Overall, the clinics' culture had more internal than external focus and need improvement on customer focus, capability development and coordination and integration. There were no significant differences in cultural traits between the clinics with various levels of implementation fidelity of the ICDM model. However, there were differences in the results of the culture by the health districts.

The leadership of the clinics (at facility and district levels) need to explore ways of engaging the patients and staff members on how to purposefully shape the culture to improve healthcare services. The weaker cultural traits that need enrichment are customer focus, capability development, and coordination and integration to make the context more conducive for the implementation of an intervention like the ICDM model that promotes coordinated, integrated, patient-centred care. In addition, evaluations on how staff attitudes and buy-in to the ICDM model principles may affect organisational culture is also important. The results of this study can also be used to set targets for improvements on organisational cultural traits and indices that are essential as the South African healthcare system is being reformed in preparation for the implementation of the national health insurance.

\section{Author affiliations}

${ }^{1}$ Perinatal HIV Research Unit, Faculty of Health Sciences, University of the Witwatersrand, Johannesburg-Braamfontein, Gauteng, South Africa ${ }^{2}$ Public Health Medicine, School of Public Health and Family Medicine, University of Cape Town, Cape Town, Western Cape, South Africa

${ }^{3}$ School of Public Health, Faculty of Health Sciences, University of the Witwatersrand, Johannesburg-Braamfontein, Gauteng, South Africa

${ }^{4}$ Health Economics Unit, School of Public Health and Family Medicine, University of Cape Town, Cape Town, Western Cape, South Africa

${ }^{5}$ Statistics and Data Management Centre, Faculty of Health Sciences, University of the Witwatersrand, Johannesburg-Braamfontein, Gauteng, South Africa ${ }^{6}$ MRC Epidemiology Unit, University of Cambridge, Cambridge, UK

Acknowledgements We would like to thank the two health districts management for granting permission to conduct the study. We are also grateful to the 90 healthcare workers that were willing to participate in the study.

Contributors LL was involved in the conception, study design, data collection, data cleaning and analysis and writing of the manuscript. NK was involved in critical review and editing of the manuscript. $\mathrm{KO}$ contributed in the data analysis, interpretation of results and review of the manuscript. MK, OA and TO have contributed to the conception, study design and critical review of the manuscript.

Funding This work was supported by the South African Medical Research Council (SA MRC) under a Self-Initiated Research Grant (grant number: 494184).

Disclaimer The views and opinions expressed are those of the authors and do not necessarily represent the official views of the SA MRC.

Competing interests None declared.

Patient consent for publication Not required.

Ethics approval Ethics approval for this study was obtained from the University of Cape Town (Ref: 127/2018) and the University of the Witwatersrand (Ref: R14/49) Human Research Ethics Committees. The Gauteng and North West Provincial departments of health also provided administrative approvals. Each of the healthcare workers interviewed provided written informed consent to participate in the study.

Provenance and peer review Not commissioned; externally peer reviewed.

Data availability statement Data are available in a public, open access repository. The data on Organizational Culture and the Integrated Chronic Diseases Management Model Implementation Fidelity in South Africa is available on Figshare via the following URL: https://doi.org/10.6084/m9.figshare.11365721.v2

Open access This is an open access article distributed in accordance with the Creative Commons Attribution Non Commercial (CC BY-NC 4.0) license, which permits others to distribute, remix, adapt, build upon this work non-commercially, 
and license their derivative works on different terms, provided the original work is properly cited, appropriate credit is given, any changes made indicated, and the use is non-commercial. See: http://creativecommons.org/licenses/by-nc/4.0/.

ORCID iD

Limakatso Lebina http://orcid.org/0000-0001-6825-0573

\section{REFERENCES}

1 Jardine MJ, Kasiske B, Adu D, et al. Closing the gap between evidence and practice in chronic kidney disease. Kidney Int Suppl 2017;7:114-21

2 WHO. A guide to implementation research in the prevention and control of noncommunicable diseases. Geneva; Switzerland: World Health Organization, 2016.

3 Bates DW, Kuperman GJ, Wang S, et al. Ten commandments for effective clinical decision support: making the practice of evidencebased medicine a reality. J Am Med Inform Assoc 2003;10:523-30.

4 Measure. Implementation research technical Working group, fundamentals of implementation research, 2012.

5 Aarons GA, Hurlburt M, Horwitz SM. Advancing a conceptual model of evidence-based practice implementation in public service sectors. Adm Policy Ment Health 2011;38:101007s1048801003277:4-23.

6 Sanson-Fisher RW. Diffusion of innovation theory for clinical change. Med J Aust 2014;6.

7 Albers B, Mildon R. Implementation best practice: a rapid evidence assessment. Sydney, Australia: Parenting Research Centre for the Royal Commission into institutional Response to Child Sexual Abuse, 2016.

8 Swensen S, Mohta N. Leadership survey: organizational culture is the key to better healthcare, 2019. Available: https://catalyst.nejm.org/ organizational-culture-better-health-care/ [Accessed 31 Oct 2019].

9 Mannion R, Davies H. Understanding organisational culture for healthcare quality improvement. BMJ 2018;363:k4907.

10 Denison RD, Neale WS. Denison organizational culture survey. The facilitator guide, 1999.

11 Denison Consulting. Getting started with your Denison organizationa culture survey, 2009. Available: https://www.denisonconsulting.com/ docs/CultureGettingStarted/UsersGuideV7.pdf [Accessed 31 Oct 2019].

12 Schneider B, Ehrhart MG, Macey WH. Organizational climate and culture. Annu Rev Psychol 2013;64:361-88.

13 Yang LJ, Harry Killey; Herbert B. The relationship between organisational culture and effectiveness in the Western Cape banking industry. Cape Town, South Africa: Cape Peninsula University of Technology, 2009.

14 Ceaușu I, Murswieck R, Kurth B, et al. The organizational culture as a support of innovation processes. IJAEMR 2017;2:2392.

15 Christensen M. Communication as a strategic tool in change processes. Int J Bus Commun 2014;51:359-85.

16 Curry LA, Brault MA, Linnander EL, et al. Influencing organisational culture to improve hospital performance in care of patients with acute myocardial infarction: a mixed-methods intervention study. BMJ Qual Saf 2018;27:207-17.

17 Braithwaite J, Herkes J, Ludlow K, et al. Association between organisational and workplace cultures, and patient outcomes: systematic review. BMJ Open 2017;7:e017708.

18 Ahmady GA, Nikooravesh A, Mehrpour M. Effect of organizational culture on knowledge management based on Denison model. Procedia Soc Behav Sci 2016;230:387-95.

19 Ginossar T, Oetzel J, Hill R, et al. Hiv health-care providers' burnout: can organizational culture make a difference? AIDS Care 2014;26:1605-8.

20 Zwaan L. Assesing organisational culture in a private hospital in Western Cape. Universtiy of Western Cape: Faculty of Economic and Management Science, 2006.

21 Scott T, Mannion R, Davies $\mathrm{H}$, et al. The quantitative measurement of organizational culture in health care: a review of the available instruments. Health Serv Res 2003;38:923-45.
22 Prem S. The adaptation and evaluation of a measure of organizational culture in the mining industry in South Africa. University of South Africa, 2011.

23 Davidson G, Coetzee M, Visser D. Organisational culture and financial Perfomance in a South African investment bank. SA $j$ ind 2007;33:38-48.

24 Denison D, Janovics J, Young JaC HJ. Diagnosing organizational cultures: validating a model and method, 2006.

25 SA Department of Health. Integrated chronic disease management manual, a step-by-step guide for implementation. South Africa: National Department of Health, 2012.

26 Mahomed $\mathrm{OH}$, Asmall S, Voce A. Sustainability of the integrated chronic disease management model at primary care clinics in South Africa. Afr J Prim Health Care Fam Med 2016;8:e1-7.

27 Statistics South Africa.. Mortality and causes of death in South Africa findings from death notification statistics South Africa, Pretoria. South Africa, 2014

28 UNAIDS. Hiv and AIDS estimates, 2019. Available: https://www unaids.org/en/regionscountries/countries/southafrica

29 Oni T, Youngblood E, Boulle A, et al. Patterns of HIV, TB, and noncommunicable disease multi-morbidity in peri-urban South Africa- a cross sectional study. BMC Infect Dis 2015;15:s12879-015.

30 Conmy A. South African health care system analysis. Public Health Review 2018;1:1-8.

31 Keeton C. Bridging the gap in South Africa. Bull World Health Organ 2010;88:803-4.

32 Hunter JR, Chandran TM, Asmall S, et al. The ideal clinic in South Africa: progress and challenges in implementation. Durban, South Africa, 2017.

33 Coleman K, Austin BT, Brach C, et al. Evidence on the chronic care model in the new millennium. Health Aff 2009;28:75-85.

34 Lebina L, Alaba O, Kawonga M, et al. Process evaluation of fidelity and costs of implementing the integrated chronic disease management model in South Africa: mixed methods study protocol. BMJ Open 2019;9:e029277.

35 Lebina L, Alaba O, Ringane A, et al. Process evaluation of implementation fidelity of the integrated chronic disease management model in two districts, South Africa. BMC Health Serv Res 2019;19:965.

36 Kawonga M, Blaauw D, Fonn S. The influence of health system organizational structure and culture on integration of health services: the example of HIV service monitoring in South Africa. Health Policy Plan 2016;31:1270-80.

37 REDCap. Technical review, 2014.

38 IBM Corp. Ibm SPSS statistics for Maclntosh. version 25.0. Armonk, NY: IBM Corp, 2017.

39 Rao V. Innovation through employee engagement. Asia Pacific Journal of Advanced Business and Social Studies2016;2:337-45.

40 Brooke-Sumner C, Petersen-Williams P, Kruger J, et al. 'Doing more with less': a qualitative investigation of perceptions of South African health service managers on implementation of health innovations. Health Policy Plan 2019;34:132-40.

41 Mash RJ, Govender S, Isaacs A-A, et al. An assessment of organisational values, culture and performance in Cape town's primary healthcare services. South African Family Practice 2013:55:459-66.

42 Zachariadou T, Zannetos S, Pavlakis A. Organizational culture in the primary healthcare setting of Cyprus. BMC Health Serv Res 2013;13:112.

43 Willis CD, Saul J, Bevan $\mathrm{H}$, et al. Sustaining organizational culture change in health systems. J Health Organ Manag 2016;30:2-30.

44 Rispel LC, de Jager P, Fonn S. Exploring corruption in the South African health sector. Health Policy Plan 2016;31:239-49.

45 Nkomazana O, Mash R, Phaladze N. Understanding the organisational culture of district health services: Mahalapye and Ngamiland health districts of Botswana. Afr J Prim Health Care Fam Med 2015;7:1-9.

46 Hung DY, Leidig R, Shelley DR. What's in a setting?: influence of organizational culture on provider adherence to clinical guidelines for treating tobacco use. Health Care Manage Rev 2014;39:154-63. 